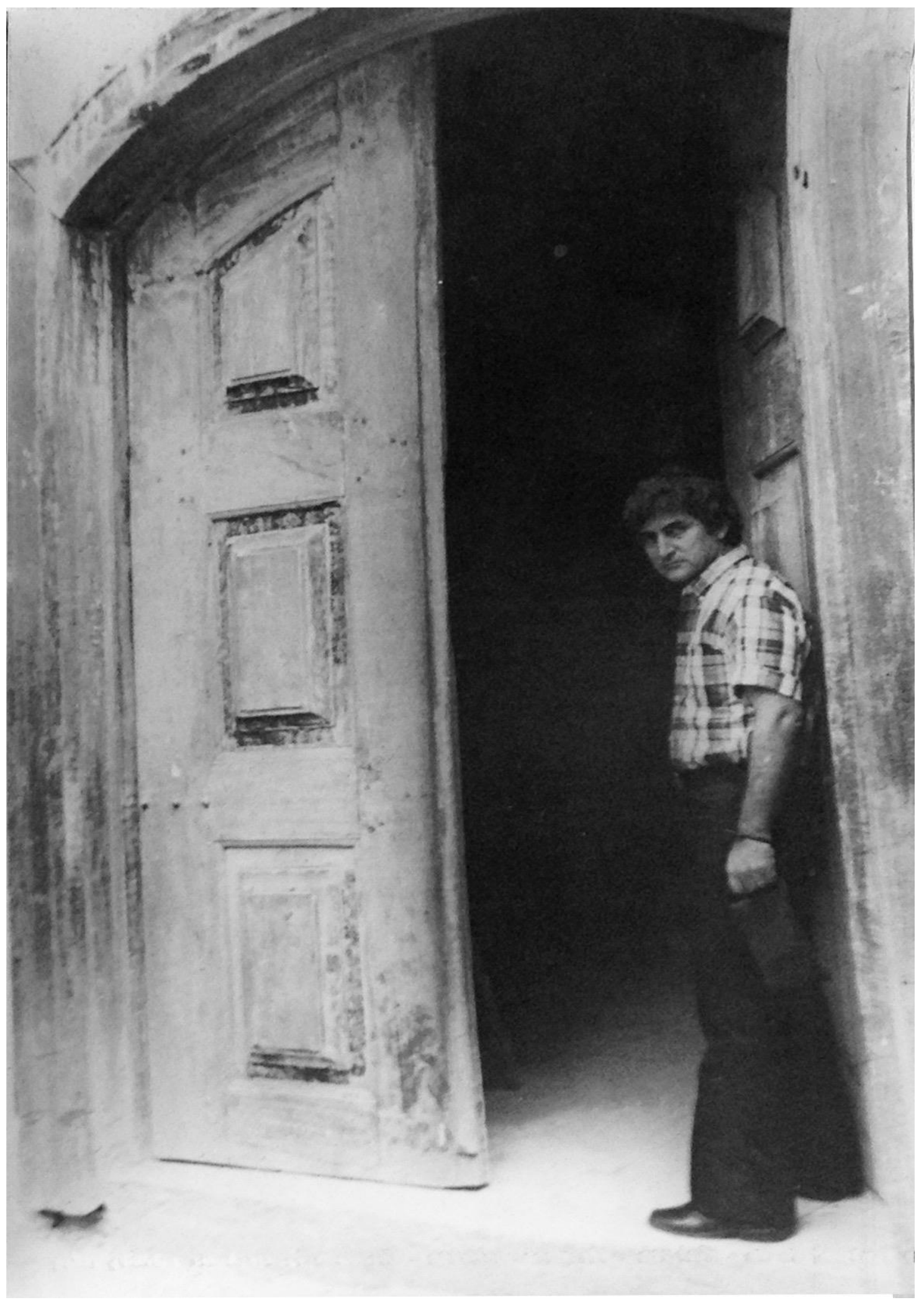

Franco Terranova na porta da terceira sede da Petite Galerie na Rua Barão da Torre em Ipanema, década de 1970. Arquivo: PG 


\section{A Petite Galerie, Franco Terranova e o circuito de arte no Rio de Janeiro,}

1954-1988

Gabriela Caspary Corrêa ${ }^{1}$

Resumo: Esta pesquisa propõe uma biografia da Petite Galerie (PG), galeria de arte que funcionou no Rio de Janeiro e em São Paulo entre 1954 e 1988, pontuada por um exame da trajetória de seu principal sócio, o marchand e escritor Franco Terranova (1923-2013).

Palavras chave: Petite Galerie, Franco Terranova, galeria de arte, circuito de arte, Rio de Janeiro

\section{Petite Galerie, Franco Terranova and the art circuit in Rio de Janeiro,}

Abstract: This research proposes a biography of the Petite Galerie (PG), an art gallery that operated in Rio de Janeiro and São Paulo between 1954 and 1988, punctuated by an examination of the trajectory of its main partner, the marchand and writer Franco Terranova (1923-2013).

Key words: Petite Galerie, Franco Terranova, art gallery, art circuit, Rio de Janeiro

${ }^{1}$ Gabriela Caspary (1971) vive e trabalha no Rio de Janeiro. Mestra em história e crítica de arte pelo PPGArtes UERJ e bacharel em história da arte pelo Instituto de Artes da UERJ. Trabalha com programação visual desde 1994. A partir de 2007, a frente da produtora Espaço Donas Marcianas Arte e Comunicação, presta serviços na área de produção artística, programação visual, design e arte gráfica. Desenvolve, também, trabalho autoral em artes visuais com experiências no campo da gravura. 


\section{Introdução}

A Petite Galerie (PG) foi uma galeria de arte que funcionou no Rio de Janeiro e em São Paulo entre 1954 e 1988. A história da PG confunde-se com a vida de Franco Terranova, italiano, poeta, marchand, galerista e único sócio que se manteve no decorrer dos 34 anos de funcionamento da galeria.

O período de atuação da PG, na segunda metade do século $\mathrm{XX}$, caracteriza-se por acontecimentos marcantes tanto para história da arte quanto para a história do Brasil. 0 suicídio de Vargas em 54, o governo de Juscelino Kubischek, a inauguração de Brasília, a ditadura militar, o milagre econômico na década de 1970, a abertura política e a hiperinflação que culminou com o Plano Collor nos anos 1980 formaram o cenário político-social onde a PG atuou. Do ponto de vista da história da arte podemos citar como momentos marcantes a valorização da arte moderna nos anos 50, os movimentos concreto e neo-concreto, as discussões em torno do objeto, o surgimento do conceito de arte pós-moderna sugerido por Mário Pedrosa, a nova figuração, o experimentalismo dos anos 70 e o retorno à pintura nos anos 80 .

O desenvolvimento da presente pesquisa aponta para a consolidação da biografia da PG, procurando entender a formação do circuito de arte no Brasil, com foco no Rio de Janeiro, em um panorama que compreende a passagem do moderno ao contemporâneo. No âmbito destas transformações pode-se observar a reformulação da ideia de galeria de arte no Brasil, passando de espaços comerciais voltados para a venda de livros e artigos para decoração até chegar ao que entendemos como galeria de arte hoje. A produção artística e crítica também sofre alterações no desenvolvimento da segunda metade do século XX; esse trânsito foi estudado a partir das escolhas de Franco Terranova.

Em 1955 o crítico Jayme Maurício sugeriu uma proto-história da PG ao comentar em nota no jornal Correio da Manhã que a galeria teria iniciando sua $2^{\underline{a}}$ fase com a entrada de Franco Terranova na gestão do negócio. A PG foi aberta em 1953 pelo 
artista ítalo-peruano Mario Agostinelli, mas este período inicial não tem características marcantes no percurso da PG, sendo assim, este trabalho considera o ano de 1954 como a data inaugural da vida da galeria. Frederico Morais no texto $P G$, escrito para o catálogo da exposição Petite Galerie (1954-1988) uma visão da arte brasileira que aconteceu no Paço Imperial em 1996, aponta três fases na trajetória da galeria, que estão relacionadas aos endereços e aos sócios que mudaram no decorrer do tempo. As três fases identificadas por Morais são aproveitadas neste trabalho. No entanto, partir da análise do fluxo de atividades da galeria apuradas por esta pesquisa, uma 4⿳亠丷厂 fase foi identificada, e tem relação com as transformações econômicas e culturais dos anos 1980.

Com base no levantamento realizado para esta pesquisa foram identificados, nos 34 anos de funcionamento da PG, cerca de 600 eventos entre exposições, leilões, salões, concursos, palestras, cursos, lançamentos de livros, apresentações musicais, de teatro, de dança, de cinema e vídeo. Passaram pela galeria mais de 160 artistas durante as décadas de 1950-80, destacando-se Alfredo Volpi, Milton Dacosta, Fraz Krajcberg, Maria Leontina, Agnaldo dos Santos, Guignard, Mario Cravo Jr., Ismael Nery, Rubem Valentim, Roberto Magalhães, Maria Bonomi, Farnese de Andrade, Wanda Pimentel, Carlos Vergara, Amélia Toledo, Artur Barrio, Antonio Manuel, Cildo Meireles, Jac Leirner, Frida Baranek, Cristina Salgado, Ernesto Neto, entre outros. 


\section{Franco Terranova e a 1ํㅡㄹ fase da PG}

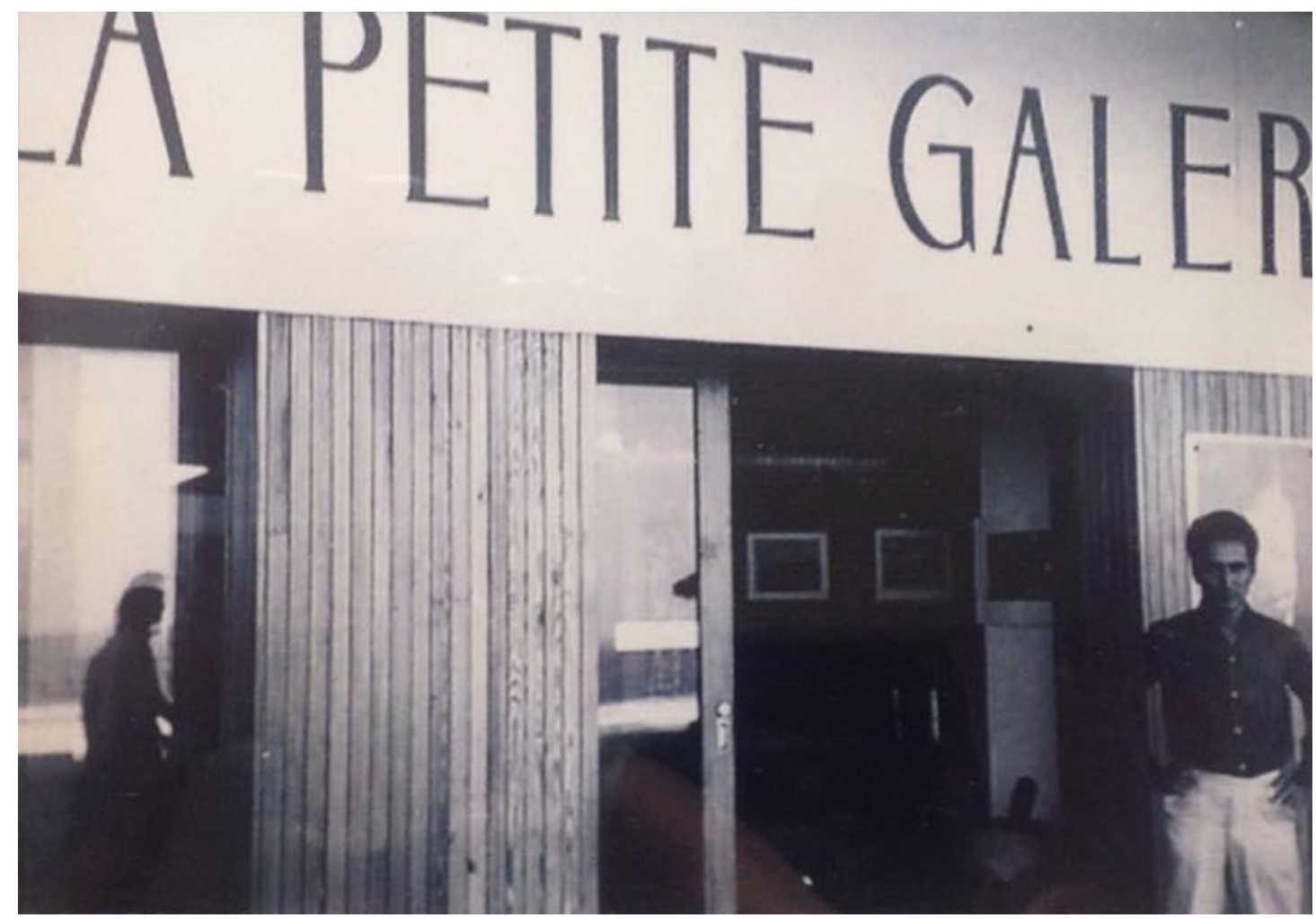

Franco Terranova em frente da primeira Petite Galerie na Av. Atlântica em Copacabana, anos 1950. Arquivo: PG.

Franco Terranova nasce em Nápoles em 1923, filho de um nobre latifundiário da região de Crúcoli, na Calábria, onde passa suas férias de infância. Na juventude participa de um grupo amador de pesquisa sobre literatura, cinema, teatro e música americana. Sua mocidade é atravessada pela $2^{\text {a }}$ Guerra Mundial que começa quando ele tem 16 anos. Com o aprofundar do conflito seu grupo de amigos dispersa-se, alguns vão servir (como Franco), uns fogem e outros morrem em combate.

Terranova chega ao Rio de Janeiro com 24 anos em 1947. Os primeiros tempos no Brasil foram de dificuldades. Interessado em arte e cultura, logo faz amizade com 
pessoas ligadas à área. Como não consegue estabelecer-se no Rio, vai para São Paulo onde trabalha como almoxarife nas industrias Matarazzo por indicação de seu pai. Não se adapta ao trabalho e foge para o Paraná. Em sua bagagem leva trabalhos de artistas como Pancetti, Castagnetto e acadêmicos. Passa um ano no Sul, organiza diversas exposições, como não vende nada, decide promover sorteios das obras em escolas e prefeituras.

De volta ao Rio em 1954, Terranova assume o negócio de Agostinelli. 0 primeiro endereço foi em Copacabana à Av. Atlântica, 2964-C ao, lado do cinema Rian (hoje Hotel Pestana). A galeria foi ponto de efervescência cultural na década de 1950. Além da loja (4x5m), o espaço contava com uma cave, com o dobro do tamanho da parte superior com o pé direito baixo de 1,80m. Era aí que aconteciam as exposições e as tertúlias, que ganharam prestígio na vida cultural da cidade. A PG passou a ser mais um ponto de encontro no bairro para além da praia, da missa, do cinema, da sorveteria.

A partir do inventário das atividades realizadas na galeria após 1954, é possível notar a pluralidade nas escolhas entre as tendências da arte moderna daquele período. Nos 5 anos de atuação de sua 1a fase, a PG apresentou 62 exposições individuais e 22 coletivas. Propôs um programa heterogêneo de arte moderna com trabalhos figurativos, expressionistas, abstratos, concretos e também arte popular, apresentando artistas veteranos e novos expoentes, indicando que mais do que uma galeria de arte moderna, era um espaço regido por um olhar moderno. A partir destes dados pode-se traçar um panorama do que se produziu no Brasil até ali.

A primeira exposição realizada sob a gestão de Terranova na PG foi com José Pancetti em outubro de 1954. Aos 50 anos de idade, Pancetti era um artista consagrado $^{2}$. O Correio da Manhã menciona o fato "incomum e arriscado" 3 de uma

\footnotetext{
2 Esta exposição, além de ser o marco do começo do trabalho de Terranova na PG, marca o começo da coleção de Gilberto Chateubriand. A tela "Praia de Itapuã" (1953), presente na mostra, foi regalada pelo artista a Chateubriand, sendo a pintura inaugural da coleção que encontra-se hoje em comodato no MAM RJ.

${ }^{3}$ Correio da Manhã, quarta feira 27 de outubro de 1954, Ed. 18885.
} 
galeria comercial apresentar telas de um único pintor. A mostra foi prolongada devido ao sucesso.

As lojas que negociavam arte naquele momento diversificavam suas atividades vendendo outros tipos de produtos como antiguidades, molduras ou livros, para viabilizar o negócio. A concepção de galeria de arte, espaço especializado para venda e fruição de arte, era praticamente desconhecido. 0 público consumidor de arte também era escasso, restrito a poucos colecionadores e um punhado de boêmios e bacharéis esclarecidos. Os jornais desenvolveram um trabalho de divulgação da arte e de formação de plateia. Jayme Maurício e Mário Barata no Correio da Manhã e Diário de Notícias, respectivamente, se dedicaram a esta empreitada, e a PG foi um agente deste processo. Estes críticos tiveram o mérito de "transformar acontecimentos de arte em fatos jornalísticos" (Morais, 1996, p.51). Tal empenho passa pelo desejo de modernização cultural e pela constituição do gosto pela arte.

É preciso ajudar quem tanto se esforça por um ideal artístico elevado. Nada impediria a 'Petite Galerie" de apresentar pintores 'vendáveis', facilmente aceitos por sua habilidade em agradar ao grande público, ao comprador artisticamente mal informado e não educado; [...] (Jayme Maurício, 27 de abril de 1955, Correio da Manhã, ed. 19043)

[...] os locais da Petite Galerie estão sempre à disposição de todos os interessados nas manifestações plásticas do país, seja porque a característica galeria da Av. Atlântica é uma das instituições que luta contra o mau gosto e a tapeação estética corriqueira entre nós. (Mário Barata, 22 de novembro de 1956, Diário de Notícias, ed. 10443)

Entre os artistas que tornaram-se grandes amigos de Terranova e expuseram em todas as fases da galeria estão: Emeric Marcier, Milton Dacosta, Maria Leontina e Alfredo Volpi que teve sua primeira exposição individual no Rio de Janeiro na PG em 1955. Frans Krajcberg também faz parte desta lista de amigos-artistas que mantiveram vinculo longo com a galeria e seu dono, sendo um dos jovens artistas que realizou sua primeira individual no Rio de Janeiro nos anos 1950 na PG.

Desde que assumiu a galeria Terranova enfrentou problemas financeiros para manter o espaço funcionando. 0 poeta, desde sempre, teve um olhar aguçado para as questões da arte e dificuldades na gestão comercial. Com o objetivo de arrecadar 
fundos para amenizar os obstáculos na manutenção de um espaço comercial exclusivo de arte, Terranova juntamente com um grupo de amigos frequentadores da galeria fundam o Clube de Amigos da PG, tendo como sócio nº 1, Jean Boghici. Entre suas atividades eram realizadas: reuniões; sorteios de obras de arte, livros e ingressos para peças de teatro; palestras e apresentações musicais.

O Clube de Amigos da PG deu certo, mas cresceu muito e gerou conflitos. Suas atividades eram anunciadas nos jornais e os interesses do grupo que assumiu a diretoria passaram a divergir das intenções de Terranova. No ano de 1957 o clube se desliga da PG e passa a se chamar Círculo de Amigos da Arte.

Como a venda de obras de arte não era suficiente para manter o funcionamento da galeria e a autonomia financeira de seu gestor, o exercício de outras atividades profissionais foram necessárias. Jean Boghici, testemunha ocular deste período em que a galeria esteve entre exposições de sucesso e a iminência de encerramento, comenta:

Apesar da doçura da vida nos trópicos, da praia, Franco vivia numa corda bamba socorrido por seus providenciais amigos, André Spitzman Jordan e José Pessoa de Queirós. Vestido com refinada simplicidade, roupas leves como convinha ao calor do Rio de Janeiro, desenhadas por ele mesmo e confeccionadas por hábeis mãos de costureiras do subúrbio, passava as manhãs na praia com apenas uma barra de chocolate para enganar a fome e a tarde ia vender gravatas e outras miudezas nesses mesmos subúrbios, já que os pintores que ele expunha não vendiam quase nada. (Boghici, Jean. Petite Galerie 1954 - 1988: uma visão da arte brasileira, 1996, p. 115)

Para tentar contornar esta situação difícil, José Carvalho - um dos donos das empresas Ducal ${ }^{4}$ onde Boghici trabalhava como vitrinista -, contrata Terranova criando o departamento de roupas RELAX, pelo qual ele seria responsável, desenvolvendo uma linha de trajes masculinos com o mesmo princípio das vestimentas que fazia para si próprio.

\footnotetext{
${ }^{4}$ A Ducal Roupas foi uma rede de lojas de roupas masculinas brasileira de sucesso nas décadas de 1950 e 1960. Seu nome, além de remeter ao nobre título de duque, também era a junção das sílabas das palavras "duas calças", pois quem comprava um paletó e uma calça ganhava outra mais barata e ficava, assim, com duas calças. A promoção deu fama à empresa junto com o seu sistema de crédito. Fonte: https://pt.wikipedia.org/wiki/Ducal
} 
Como parte das estratégias de incrementar as vendas na galeria, Terranova investiu também em suportes alternativos à pintura a óleo. Desenhos, gravuras e pinturas com tinta guache em pequenos formatos foram comercializadas na PG. Em 1957, a PG investiu na gravura apresentando individuais de Rossini Perez, Lívio Abramo e Hansen Bahia; Edith Bering, Darel e Marcelo Grassman participaram de coletivas; no fim do ano acontece ainda uma coletiva com Ana Leticia, Vera Bocaiuva, Ernesto Lacerda, Olímpio Araújo e Rossini Perez.

Compondo o programa híbrido da PG está a difusão da "arte popular" e de artistas considerados "primitivos". Entre estes artistas podem ser citados; Djanira, Heitor dos Prazeres, Agnaldo dos Santos, Francisco Guarany (Mestre Biquiba Guarany), Mestre Vitalino e esculturas de ex-votos do Nordeste.

Mesmo com todos os esforços e apoio de artistas e jornalistas, em dezembro de 1957 Terranova não consegue manter a PG em funcionamento, encerrando assim suas atividades. A galeria fica fechada por um ano e meio até o segundo semestre de 1959. Neste período de recesso, a relação de Franco Terranova e José Carvalho se amplia para uma sociedade. 0 primeiro negócio foi uma loja de relógios chamada Old Clock instalada no espaço da PG no cine Rian. Entre o trabalho na Ducal e a loja de relógios, Terranova realiza uma viagem ao nordeste como parte de sua parceria com José Carvalho. A viagem aconteceu na companhia do amigo Agnaldo dos Santos e tinha como objetivo resgatar carrancas do rio São Francisco e outras relíquias de arte popular para comercialização no Rio.

Em agosto 1959, a PG reabre com uma coletiva chamada "30 artistas do Brasil". A galeria promove também um concurso para criação de cartões de Natal. Nesse ano, passa a trabalhar na galeria a jovem bailarina Rossella, que vai tornar-se esposa de Terranova em 1962. Rossella, grega de nascença e italiana de origem, chega ao Brasil em 1945. Filha de diplomatas, vem com a família para o Brasil abrir a embaixada da Itália no Rio e o consulado em Santos. 


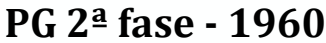

A transição para o que chamamos de $2^{\text {a }}$ fase começa com o retorno das atividades da galeria em 1959. 0 aprofundamento desta mudança se dá em 1960 com a entrada oficial de José Carvalho (Lojas Ducal). 0 ingresso de José Luiz Magalhães Lins (diretor do Banco Sotto Maior e do banco Nacional de Minas Gerais) como sócio também foi um marco decisivo deste momento. Os dois empresários trazem o aporte de capital e a expertise nos negócios para a transição da "década heroica" para a "década de ouro", como nomeou Franco Terranova 5 em relação à atuação da PG nos anos 50 e 60 respectivamente.

A questão central da $2^{\mathrm{a}}$ fase da PG foi o avanço na profissionalização do mercado de arte e o desenvolvimento de mecanismos comerciais nesta área. Para além das exposições regulares na galeria, foram firmados contratos de exclusividade com artistas; implantadas as vendas de obras de arte a prazo; realizados leilões a prazo e leilões de parede; e lançados prêmios, salões e concursos.

O primeiro contrato assinado pela PG, segundo depoimento de Carlos Scliar ${ }^{6}$, foi com Emeric Marcier. Durante o levantamento documental do acervo da galeria não foram encontrados contratos. A partir de relatos de artistas e notícias de jornal pôde-se apurar, além de Emeric Marcier, outros artistas que assinaram contratos com a PG no início de sua segunda fase. Entre eles: Di Cavalcanti, Guignard, Agnaldo dos Santos, Milton Dacosta, Maria Leontina, Loio Pérsio, Carlos Scliar, Glauco Rodrigues, Rubem Valentim, Gastão Manoel Henrique e Ivan Marqueti. Sobre o funcionamento dos contratos, José Carvalho fala em entrevista a Jayme Maurício:

JM - Quais são as bases de seus entendimentos com os artistas brasileiros de um modo geral? E com os estrangeiros?

JC - De um modo geral as bases são as mesmas adotadas na Europa e no mundo inteiro. Há diversos tipos de contrato, sendo o mais usual o sistema

\footnotetext{
${ }^{5}$ Fonte: https://www.youtube.com/watch?v=FP0sRrt5Hu8

6 Petite Galerie 1954-1988: uma visão da arte brasileira. Paço Imperial no Rio de Janeiro, 1996, p.116.
} 
pelo qual o artista recebe uma mensalidade fixa em troca de um número determinado de quadros. (Correio da Manhã, 11 de agosto de 1962, Ed. 21288)

No sistema de vendas a prazo, as obras pertencentes a galeria eram entregues ao cliente no momento da compra, sendo o pagamento parcelado sem juros. As obras expostas em consignação, caso houvesse comprador interessado, eram adquiridas do artista à vista pela galeria e financiadas a prazo para o cliente. Em conversa com Ferreira Gullar, Terranova disse-se surpreso com o resultado deste tipo de venda. "Conseguimos manter o freguês que comprava à vista e ganhamos novos compradores. E os que compravam à vista também adotaram o sistema de financiamento" (Jornal do Brasil, 1960, Ed. 00258).

Em 24 de outubro de 1960 foi inaugurada a nova sede da PG, instalada em uma loja no edifício projetado por Oscar Niemeyer na rua Teixeira de Melo (Praça General Osório, 53, Ipanema). A galeria, com projeto arquitetônico e de iluminação assinados por Sérgio Bernardes, ocupava uma área total de $240 \mathrm{~m}^{2}$ sendo 160 destinados a exposições, o "pequena" ficou apenas no nome. A marca e o design dos catálogos foram criação de Aloísio Magalhães. 0 mobiliário foi desenhado por Sérgio Rodrigues, vizinho de praça com sua loja OCA. A praça passa a ser um ponto de efervescência cultural abrigando bares, restaurantes (Jangadeiros, Fox, RioNápoles), galerias de arte, lojas de design (OCA, Tenreiro, Contemporânea e Damarta), teatros e cinema (Cinema Pirajá, Teatro Poeira, Teatro e galeria Santa Rosa e Teatrinho de Bolso). 


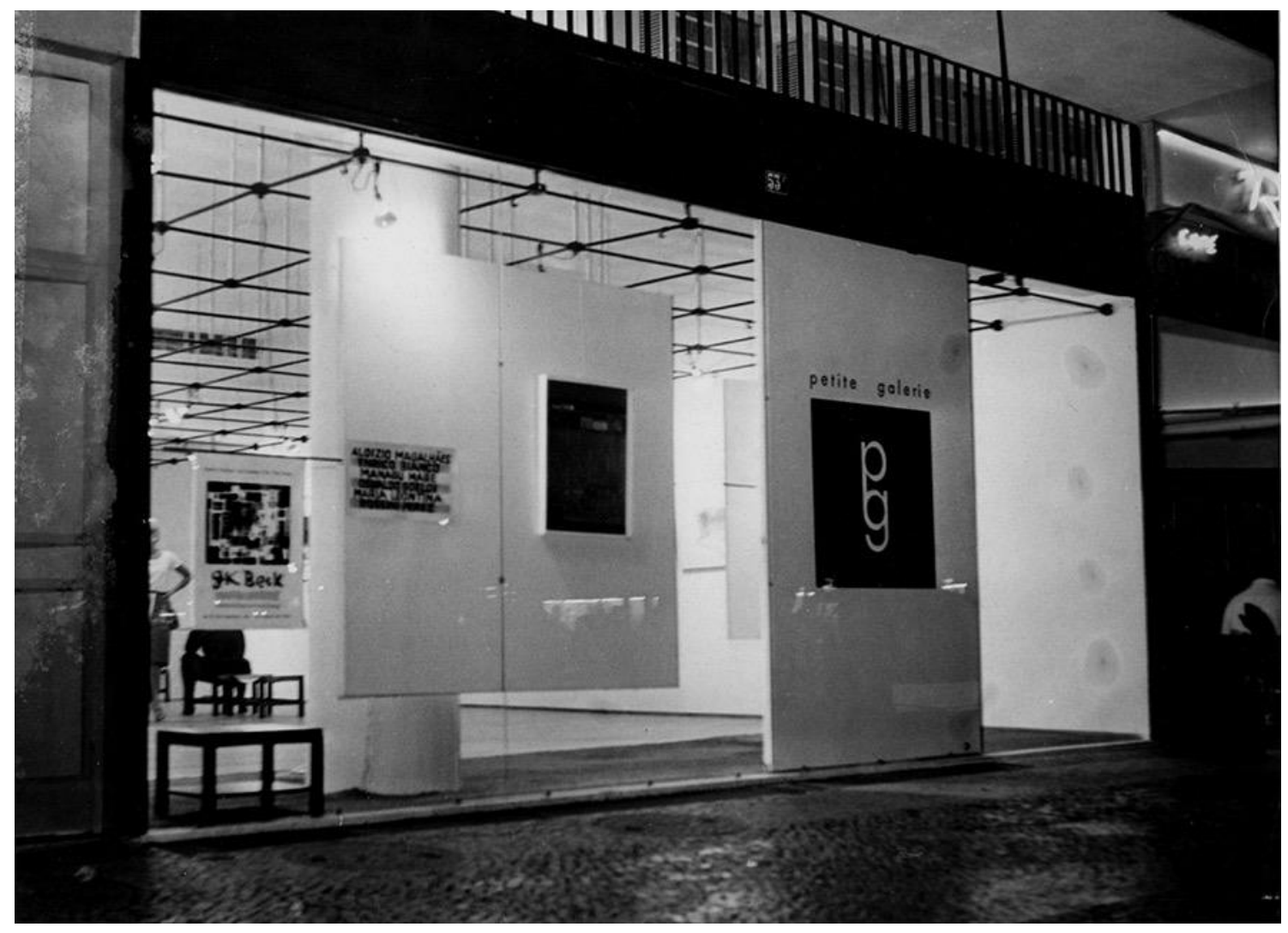

Fachada da Petite Galerie na Praça General Osório em Ipanema, década de 1960. Arquivo:PG.

A exposição de abertura teve Guignard como estrela, o catálogo contou com texto de apresentação de Rubem Braga. A exposição teve sucesso de vendas e em uma semana o Jornal do Brasil noticiou a venda de 20 dos 24 quadros expostos e 9 dos 10 desenhos.

O primeiro leilão organizado pela PG aconteceu em agosto de 1964 no Copacabana Palace e trouxe a novidade de ser também por pagamento a prazo. 0 sistema implantado estabelecia que o lance oferecido corresponderia ao valor da prestação a ser paga em 10 parcelas sem juros. Posteriormente, as parcelas para este tipo de leilão a prazo foram sendo modificadas e no fim da década de 60, com o avanço da inflação, só os lances para 5 parcelas seriam mantidos sem juros.

O leilão de 64 fez sucesso com procura do público e repercussão nos jornais, tendo reunido mais de 1000 pessoas no Copacabana Palace. Além dos leilões a prazo realizados na presença do leiloeiro a PG realizou leilões de parede. Nestes, o 
aspirante comprador deveria marcar seu nome e o preço da parcela inicial numa folha de papel fixada ao lado da peça exposta na galeria. 0 pagamento deveria ser feito em 10 prestações sem juros. Ao fim do prazo estipulado para o leilão, que correspondia ao tempo da exposição das obras, o último preço marcado na folha era o lance final de arremate da obra.

Esta pesquisa apurou a realização de 7 leilões na PG no Rio de Janeiro na década de 60. Os leilões eram anunciados em vistosos anúncios de jornal, visando ampliar os limites do mercado. Na década de 1970 o numero de leilões chegou a 42. Estes números são referentes apenas a leilões realizados no Rio de Janeiro. Durante toda a década de 70 foram realizados leilões regulares, seguindo esta tendência de mercado no Brasil. Além do Rio de janeiro, a PG organizou leilões em São Paulo, Recife, Porto Alegre e Belo Horizonte.

Observando o desenvolvimento das atividades da galeria no plano artístico em sua $2^{\text {a }}$ fase, a PG manteve a característica de apresentar uma programação diversificada. Neste período podemos observar a continuidade na parceria com artistas com obras já institucionalizadas como Guignard, Milton Dacosta, Maria Leontina, Mario Cravo Jr. e Volpi. Artistas como Palatnik, Krajcberg, Weissmann, que avançaram em suas pesquisas alcançando um reconhecimento de público e crítica, também estiveram presentes na programação da PG. Experiências como as propostas por Wesley Duke Lee e o Grupo Rex, Otto Stupakoff e Roberto Moriconi passaram por lá. Outro ponto que se tornou permanente na conduta da galeria desde a década de 50 foi o incentivo e lançamento de novos artistas. Entre os nomes da nova geração que despontou neste período estão: Glauco Rodrigues, Gastão Manoel Henrique, Maria Bonomi, Roberto Magalhães, Carlos Vergara, Farnese de Andrade, Wanda Pimentel, Regina Vater, Cildo Meireles, Maria do Carmo Secco, Carlos Fajardo, Frederico Nasser, José Resende, entre outros. Foi também na década de 1960 que a PG participou de uma reavaliação da arte moderna: o resgate da obra de Ismael Nery. Essa mostra (1966), que foi a primeira retrospectiva do artista desde sua morte em 1934, assim como alguns dos Salões organizados por Terranova, nos servem como estudos de caso 
exemplares da rotina da galeria em sua dupla ótica, mirando alternadamente a consagração do modernismo e o apoio a uma jovem produção contemporânea.

\section{Salões}

A partir do desenvolvimento das novas experiências e linguagens artísticas, o questionamento aos salões de arte moderna foi intrínseco ao momento. 0 modelo de premiação dos salões não acompanhou a produção desta geração, estando fechado, desde o século XIX, às mesmas categorias tradicionais de pintura, gravura, desenho e escultura características da arte acadêmica. Nesta conjuntura, a PG além de exposições e leilões, também realizou salões e concursos com premiações a partir da avaliação de bancas compostas por críticos e artistas. Ao todo a PG vai participar de 5 premiações na sua $2^{\underline{a}}$ fase.

Depois da realização do 1ํ Salão de Artes Plásticas em 1961 a PG se afastou das premiações até 1965 quando participa da mostra Resumo JB - IV Centenário, sendo a primeira e única vez que o evento organizado pelo Jornal do Brasil oferece prêmio em dinheiro.

Em 1966 acontece o 1ํ Salão de Abril ${ }^{7}$ organizado pela PG com exposição no MAM Rio. A característica mais importante deste salão foi a inclusão da categoria "pesquisa artística" abrindo à participação de trabalhos que não se enquadrassem nas categorias tradicionais de pintura, gravura, desenho e escultura. O Salão Bússola de 1969 propõe uma categoria como esta, que vai se chamar ETC.

Uma das questões artísticas desenvolvidas no período em que Pedrosa chamou de pós-moderno foi a discussão em torno do objeto. Este processo fez parte das pesquisas $^{8}$ iniciadas na Europa no raiar do século XX. Este desenvolvimento que culminou nos anos 1960 pode ser exemplificado pelo conceito de objetos-criados de

\footnotetext{
7 Também conhecido como Salão de Arte Jovem por ser direcionado a artistas com menos de 40 anos. ${ }^{8}$ Como exemplos destas experiências empregadas no início do século XX podem ser citaos os redymades de Duchamps, contrarelevos de Tatlin, a arquitetura supremacista de Malevich ou os «objet trouvé» surrealistas.
} 
Waldemar Cordeiro; pela teoria do não-objeto de Ferreira Gullar; ou pelas "novas estruturas para além daquelas de representação" (Oiticica, 1977, p.1) como teorizou Hélio Oiticica.

Gastão Manoel Henrique, Farnese de Andrade e Avatar Morais expuseram seus “objetos" na PG em 1966. Neste mesmo ano Frederico Morais inaugura sua coluna no jornal Diário de Notícias, onde vai propor reflexões acerca destas questões. Observando a produção deste período podemos perceber a elaboração de uma série de objetos em torno do formato caixa.

Farnese de Andrade mostrou pela primeira vez suas assemblages naquele ano. Frederico Morais intitulou a coluna que anunciou a abertura da exposição como “'Objetos achados' e Anjos Atômicos de Farnese de Andrade” ${ }^{9}$. Morais menciona que Farnese recusava-se a mostrar estes trabalhos porque precisava vender, sendo desenhos e pinturas os formatos vendáveis ${ }^{10}$. Assim, podemos observar a PG trabalhando no sentido de criar possibilidades de comercialização de um novo tipo de produção, na viabilização e divulgação da arte contemporânea.

Avatar Moraes foi um dos representantes brasileiros da V Bienal de Paris (1967) caracterizada por convocar artistas menores de 35 anos. Sua exposição na PG (1966) suscitou um debate público sobre os problemas da arte daquele momento. 0 debate aconteceu dentro da galeria e dele participaram os críticos Frederico Morais, Edyla Mangabeira, Mário Pedrosa, Harry Laus, Jayme Maurício e Antônio Bento, e os artistas Maria do Carmo Secco, Antônio Dias, Rubens Gerchman, Hélio Oiticica, Lígia Clark, Glauco Rodrigues, Gastão Manoel Henrique, Carlos Vergara, Farnese de Andrade, Pedro Escosteguy, entre outros.

Em dezembro de 1966 a PG lança as regras de participação para o Salão de Abril de 1967, conhecido como "salão das caixas", por propor como premissa obras dentro

\footnotetext{
${ }^{9}$ Frederico Morais, 'Objetos achados' e Anjos Atômicos de Farnese de Andrade, Diário de Noticias, 18 de outubro de 1966, Ed. 13471.

10 "Mas sempre recusou mostrá-las [as assemblages], preferindo exibir, numa galeria-loja de móveis, com argumento de que precisava vender, os desenhos, que considero ruins, e com os quais participou na exposição JB-Resumo." (Frederico Morais, Diário de Notícias, 1966, Ed. 13471)
} 
desta característica. Nesta mesma época do ano a Bienal de São Paulo anuncia o edital para a IX edição. A PG patrocina um prêmio de mil dólares para a categoria "obra caixa" naquela bienal.

Nesta ocasião Frederico Morais publica uma série de 3 colunas: "PG Compra Caixas a Cr\$ 500 mil”; "A Institucionalização da Vanguarda Brasileira”; e "A caixificação da vanguarda", problematizando o modelo das premiações a partir de uma proposta fechada como a caixa. A crítica ao salão abordava o que Morais chamou de "condicionamento bitolador do mercado de arte" e "a redução do conceito de Objeto, via caixa, a um nível digestivo". Os debates, que já vinham acontecendo durante o ano, intensificaram-se e expandiram-se. Em janeiro de 1967 um manifesto assinado por Antônio Dias, Carlos Vergara, Rubens Gerchman, Lygia Clark, Ligia Pape, Glauco Rodrigues, Sami Mattar, Solange Escosteguy, Pedro Escosteguy, Frederico Morais, Raimundo Colares, Carlos Zílio, Maurício Nogueira Lima, Hélio Oiticica, Ana Maria Maiolino e Renato Landin é publicado no Diário de Noticias ${ }^{11}$.

O movimento terá sequencia com a realização de uma exposição nacional do objeto e tendências afins com a denominação de "Nova Objetividade Brasileira”. (Morais, 1967, Diário de Notícias, Ed. 13544)

A ação do salão levantou a questão da influência da galeria na produção artística como fator de mercantilização, de domesticação da arte em função do mercado. 0 texto do catálogo da exposição Nova Objetividade Brasileira - que aconteceu no MAM Rio simultaneamente à exposição das obras vencedoras no "Salão das Caixas" - escrito por Hélio Oiticica apontou as seguintes proposições:

\begin{abstract}
Nova objetividade seria a formulação de um estado de arte brasileira de vanguarda atual, cujas principais características são: 1: vontade construtiva geral; 2: tendência para o objeto ao ser negado e superado o quadro de cavalete; 3: participação do espectador (corporal, táctil, visual, semântica, etc.): 4: abordagem tomada de posição em relação aos problemas políticos, sociais e éticos; 5 .: tendência para proposições coletivas e consequente abolição de "ismos" característicos da primeira metade do século na arte de hoje (tendência esta que pode ser englobada no conceito de "arte pósmoderna" de Mário Pedrosa); 6;: ressurgimento e novas formulações do conceito de antiarte. (Oiticica, 2006, p. 154)
\end{abstract}

${ }^{11}$ Publicado na coluna Artes Plásticas de Frederico de Moriais em janeiro de 1967, Diário de Notícias, Ed. 13544. 
Apesar da controvérsia, os artistas não deixaram de participar do salão. Carlos Vergara é premiado no salão, é signatário do manifesto da Nova Objetividade e participa da exposição no MAM Rio. Avatar Moraes, Gastão Manoel Henrique e Maria do Carmo Secco também participaram em ambas as efemérides.

Neste contexto, pode-se entender a questão do fim dos salões por duas perspectivas. A primeira, já abordada, teve relação com a dificuldade na adaptação dos seus formatos às novas práticas artistas que despontaram a partir dos anos 1960. A segunda foi política. 0 endurecimento do regime militar autoritário atingiu diretamente os salões oficiais. Em 1968 a II Bienal da Bahia foi censurada e as obras que já estavam montadas no Solar do Unhão foram apreendidas, estando desaparecidas até hoje. Em 1969 o Itamarati censura os artistas selecionados para a VI Bienal de Paris e o Brasil não participa da bienal. 0 departamento de censura retira trabalhos do salão de Ouro Preto já tendo feito isso em outros salões anteriores.

A censura pode ter interferido na realização dos salões oficiais mas não impediu que manifestações artísticas coletivas continuassem acontecendo. Em abril de 1970, Frederico Morais organiza o evento "Do Corpo a Terra” em Belo Horizonte (MG). Em junho acontece na PG o ciclo de exposições "Agnus Dei" com os artistas Thereza Simões, Guilherme Vaz e Cildo Meireles. Esta exposição foi um eco do que aconteceu em Belo Horizonte e no Salão Bússola.

Thereza Simões foi a primeira a expor (de 22 a 29 de junho de 1970). Ela apresentou uma versão do trabalho com carimbos que mostrou em Belo Horizonte dentro do evento organizado por Morais. Além dos carimbos, com os quais marcou as paredes da galeria, ela apresentou o trabalho "Inscrições" (telas brancas com títulos descritivos de situações).

A participação de Guilherme Vaz estava prevista para acontecer entre 30 de junho a 7 de julho, mas durou poucas horas, a polícia interrompeu a festa de inauguração. A intervenção de Vaz consistiu em afixar na porta da galeria o documento intitulado 
"Projeto de exposição para assassinatos coletivos em alta escala", um aviso em que ele se apropriava de todos os presentes na galeria.

Cildo Meireles mostrou, entre 8 e 17 de julho de 1970, os registros fotográficos e o resto do poste utilizado na experiência "Tiradentes: Totem-monumento ao preso político" apresentada no evento "Do Corpo a Terra" e 3 garrafas da série "Inserções em circuitos ideológicos: Projeto Coca-cola" (mostradas pela primeira vez em uma galeria de arte nesta ocasião).

O envolvimento de Frederico Morais com a produção artística nesta altura foi além do papel do crítico observador. Ele exerceu uma relação participativa, engajada, dentro do que ele chamou de "guerrilha artística"12. Dentro deste espírito, e como resposta ao ciclo "Agnus Dei", Frederico Morais realiza na PG a exposição "A Nova Crítica". Como experiência de ação crítica, com o objetivo de repensar os modelos da crítica de arte, Morais não escreve um texto reflexivo sobre o ciclo "Agnus Dei"; ele desenvolve trabalhos de arte como ensaio crítico.

Faz-se necessária uma profunda revisão do método crítico. Crítica poética. Não há mais obra. Não é mais possível qualquer julgamento. 0 crítico é hoje um profissional inútil. (MORAIS, 1995, p.312).

Para Thereza Simões, foi produzido um novo carimbo com a inscrição "Brasileiros retornem" em resposta ao slogan da ditadura "Brasil: Ame-o ou deixe-o" junto com o carimbo foram apresentadas correspondências trocadas com artistas que encontravam-se fora do Brasil, como por exemplo envelope endereçado a Antonio Dias em sua residência de Milão na Itália.

Em resposta a Guilherme Vaz, Morais substitui o documento original por um outro que anula o primeiro.

Para Cildo Meireles são instaladas no piso da galeria 15 mil garrafas de coca-cola, cedidas e transportadas pela empresa como resposta ao projeto "Inserções em

\footnotetext{
12 Entre as experiências de Frederico Morais no processo de desenvolvimento do seu conceito de "guerrilha artiística" podemos citar o episódio do Salão de Brasília (1967), com a situação do porco empalhado de Nelson Leirner, o evento "Do Corpo a Terra" em Belo Horizonte (1970) e os "Domingos de Criação" no MAM/Rio (1971).
} 
circuitos ideológicos: projeto Coca-cola". A intenção foi demonstrar a capacidade do mercado em absorver qualquer atitude revolucionária como parte dos meios de consumo. Em resposta ao trabalho "Tiradentes: Totem-monumento ao preso politico", Morais apresenta fotos de um monge vietnamita ateando fogo em si próprio anexadas a textos bíblicos do Gênesis e Êxodo.

A exposição "A Nova Crítica" dura apenas algumas horas, sob ameaça de invasão da galeria pela polícia. Durante os anos de chumbo a PG exerceu um papel de mediação entre o regime autoritário e a produção artística, buscando brechas para a veiculação de trabalhos e a manutenção da produção artística e crítica do momento. É também uma experiência instigante sobre um sentido expandido de uma galeria, que promove seus artistas não só por vendas mas eventos como esse insólitos para um modelo comercial mais conservador, ou mesmo em bancar formas de atuação "inusitadas", como a de Frederico. Ela transparece um tipo de agitação cultural estimulada regularmente pela PG (ou ao menos por Terranova), visto que anos antes Vergara ali realizara pela primeira vez sua instalação Berço Esplêndido, ocasião em que galeria também foi ameaçada de invasão pela polícia.

0 texto "O boom, o pós-boom e o dis-boom"13, publicado em 1976, pretendeu dar conta do desenvolvimento do mercado de arte no momento do "milagre brasileiro". O texto, através de uma revisão histórica, aponta a ausência da participação ativa do mercado brasileiro no processo de "transformações de linguagens", estando o mercado "alheio à própria construção da história da arte local". No entanto, ao observar o diálogo da PG com o desenvolvimento da arte produzida no Brasil na segunda metade do século XX, é possível perceber esta relação como "agente de ativação". Hoje, 30 anos após a publicação deste texto, com devido distanciamento histórico e com o desenvolvimento das pesquisas no campo da história da arte no Brasil, começa-se a compreender o papel do mercado de arte brasileiro neste desenvolvimento.

13 Zilio, Carlos, José Rezende, Ronaldo Brito and Waltercio Caldas. "O boom, o pós-boom e o disboom."

Opinião (Rio de Janeiro, Brazil), no. 200 [s.d.]: 25- 28. 
Ao contrário do que se passa nos mercados centrais, onde o processo de institucionalização dos trabalhos resultado sua própria inscrição no processo histórico decorrente do confronto produção/mercado, as condições de avaliação dos trabalhoso aqui mais ou menos estranhas ao mercado, em todo o caso não são detidas por elas. 0 mercado brasileiro manipula a produção já institucionalizada. (Carlos Zílio, José Rezende, Ronaldo Brito e Waltércio Caldas, 2001, p. 185)

A década de 1960, a parte das questões artísticas, mercadológicas e políticas, foi marcante na vida de Franco Terranova. Em 1962 ele casa-se com Rossella, que será sua companheira por toda vida. Nesta década nascem seus 3 primeiros filhos, Eleonora (Lola), Marco e Francesca (Keka). Nesta década, Terranova continua a desenvolver sua poesia. Em 3 de setembro de 1960, Mario Faustino, então responsável pela seção Poesia-Experiência do Suplemento Dominical do Jornal do Brasil, publica aí seu poema Girassol. Em 1973 seu primeiro livro é lançado com este nome. Em 1971 nasce sua filha mais nova Paola, que chega junto com o início da 3aㅗ fase da PG e com a mudança da galeria para a rua Barão da Torre. 


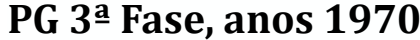

Uma das principais características da $3^{\text {a }}$ fase da PG foi o aumento na realização de leilões. Este salto acompanha a tendência geral do mercado na década de 1970. Observou-se também uma expansão das atividades de Terranova em São Paulo, que incluíram a Múltipla Galeria, a filial da PG e a galeria Arte Global. Esta expansão causou uma diluição das atividades no Rio de Janeiro, traço que também tem relação com os rumos do mercado de arte neste período.

0 avanço nas pesquisas artísticas do momento "pós-moderno" gera divergências no modo de pensar o negócio. A parceria entre Carvalho e Terranova, que marcou a trajetória da PG na década de 60, deixa de ser interessante para ambos. Carvalho, com seu perfil de homem do comércio, funda a Bolsa de Artes do Rio de Janeiro, que vai funcionar a partir de 1971 na mesma loja onde era a PG na Praça General Osório. Terranova, como poeta e homem das artes, segue com sua "pequena galeria". Em julho de 1970, Magalhães Lins se desliga da sociedade na PG, mas continua a financiar o comércio de arte através dos projetos dos ex-sócios.

Em 1971, a Petite Galerie muda-se para Ipanema, à rua Barão da Torre, 220. 0 casarão com pé-direito alto, telhas aparentes e mezanino de madeira foi construído em um terreno alugado, a partir de projeto de Terranova. A imponente porta da entrada pertenceu a uma igreja colonial mineira do século XVIII. 0 escritório dividiase entre o térreo e o primeiro andar. Nos fundos da casa havia para além da reserva técnica, um ateliê com prensa de gravura operada por Darel e estrutura para produção de molduras, fabricadas por Francisco Rodrigues de Paiva e objetos de acrílico executados por Arrigo Casalichio. A nova sede da PG foi idealizada para ser um centro de artes na cidade com sala de exposições, escritório de vendas, leilões e ateliê para produção de obras seriadas. 


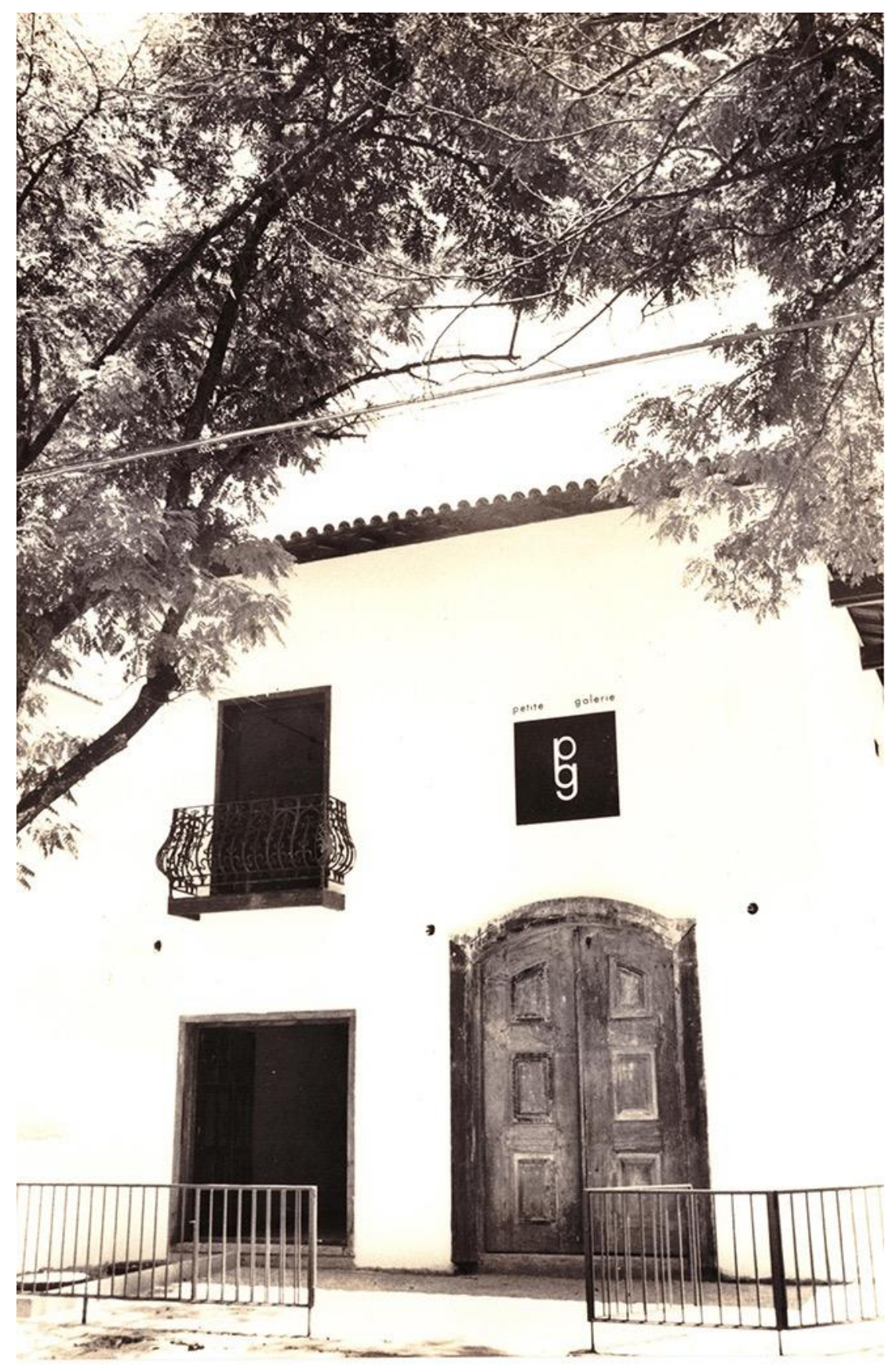

Fachada da Petite Galerie na rua Barão da Torre em Ipanema, década de 1970. Arquivo:PG.

A 3 ${ }^{a}$ fase da PG avança na discussão em torno do objeto, propondo a inserção do múltiplo no Brasil. Esta linguagem já estava sendo aplicada na Europa e nos Estados Unidos desde os anos 60. Desde a década de 1950, a PG investiu em produção seriada (gravura em metal, serigrafia e litogravura) como estratégia de alcançar preços mais 
baixos, ampliar vendas e democratizar a aquisição de obras de arte. A popularização do múltiplo no mercado exterior e o interesse em torno do objeto tridimensional foram um atrativo para Terranova.

Uma das primeiras atividades promovidas pela PG em sua nova sede foi uma exposição de múltiplos internacionais. Seguindo a tendência internacional, na qual galerias editavam séries de múltiplos, Terranova encomenda a 21 artistas brasileiros a execução de protótipos para produção com tiragem de 100 . 0 processo de incentivo à produção de múltiplos incluiu um Concurso Nacional de Múltiplos, a edição de múltiplos, e a edição um livro que foi referência para as discussões acerca do múltiplo que se estenderam durante os anos 1970.

0 aprofundamento das pesquisas iniciadas nos anos 1960 resumidas na exposição Nova Objetividade Brasileira, que gerou uma produção comumente denominada de "vanguarda", no decorrer dos anos 1970 passa a ser tratada também como "arte experimental".

Não se pense ser imediata e prática a definição de experimental. Ela supõe certa margem de dúvida, certo momento transitório entre o espírito de pesquisa inerente a toda manifestação artística que se pretenda viva e uma postura experimental verdadeiramente impositiva, marcada desde dentro pela intenção de encarar na raiz e com visão crítica o ato criador. (Roberto Pontual, Jornal do Brasil, 13 de janeiro de 1976, Ed. 00278)

Roberto Pontual, no artigo Arte Experimental (1976), que propôs um resumo dos acontecimentos de 1975 no Jornal do Brasil, aponta como principais espaços de difusão deste tipo de produção a PG, a galeria Luiz Buarque de Holanda \& Paulo Bittencourt, a galeria da Maison de France e o MAM-Rio que inicia em 75 um projeto dirigido a este tipo de proposta.

A exposição Isto é que é de Antonio Manuel na PG em 1975 apresentou um apanhado de sua produção dos anos anteriores que não tiveram o acolhimento institucional do MAM, buscando espaço para a divulgação e comercialização de um novo tipo de obras. Norma Cury em sua crítica à exposição de Antonio Manuel aponta: "a tentativa é romper com o espaço da galeria. Com trabalhos que não são comerciais nem 
comerciáveis, mas trazem sempre uma visão crítica da situação" (Cury, Jornal do Brasil, 1975, Ed. 00203).

O espaço para a artista mulher esteve aberto na PG desde o início das atividades da galeria. Neste sentido, artistas como Regina Vater e Wanda Pimentel marcaram este tipo de abordagem na PG ${ }^{14}$. Esta abertura não fez parte de um programa conceitual, como também não o foi a afinidade com a arte popular. A aproximação com as questões culturais integra o perfil da PG desde os anos 50. Terranova manteve-se aberto a receber todos os artistas independente de gênero, origem social ou étnica e opções estéticas, o seu critério partia do entendimento sobre a qualidade do trabalho em si.

0 ambíguo contexto que marca a metade final da década de 1970 - a um só tempo o início gradual e incerto de abertura política assinala um desejo sufocado pela crescente inflação - é espelhado na situação dual do sistema de arte como um todo: as novas agendas artísticas, a expectativa pela expansão são embarreiradas por limitações materiais do meio (a precariedade institucional) e sistêmicas (a ausência de uma base financeira estável que sustente o circuito). Na avaliação de Frederico Morais e Roberto Pontual ${ }^{15}$ sobre a década de 1970, foram observados, mesmo diante dos avanços, a crise no sistema expositivo, o declínio dos salões, uma pobreza nas bienais de São Paulo, uma crise na vanguarda e um esvaziamento da produção, sintetizados simbolicamente pelo incêndio no MAM em 08 de julho de 1978. É nesse ambiente que observamos a aproximação do ponto de inflexão da PG, que na década seguinte teria como desenlace sua invisível retração (financeira, pois não diminui imediatamente sua importância de agitadora cultural) até o encerramento das atividades em 1988.

\footnotetext{
${ }^{14}$ Lista de algumas das artistas mulheres que fizeram exposições individuais na PG: (1 fase) Maria Leontina, Ione Saldanha, Hilda Campofiorito, Ana Letycia, Myra Landau, Cecilia Gismondi, Edith Behring, Djanira, (2 fase) Eleonore Koch, Renina Katz, Isabel Pons, Mira Schendel, Maria Bonomi, Inge Roesler, Wilma Pascoalini, Maria do Carmo Secco, Pietrina Chacaccii, Tomie Otake, Marcia Barroso do Amaral, Wanda Pimentel, Regina Vater, (3 fase) Maria Lúcia Alvim, Solange Magalhães, Malu Fatorelli, Frida Baranek, Maria Luiza Sertório, Cristina Salgado, Jac Leirner, Lena Bergstein, entre outras.

${ }^{15}$ Frederico Morais, Um Ano decisivo, coluna Artes Plásticas, O Globo, 2 de abril, de 1975, Cultura, p. 27. Roberto Pontual, Jornal do Brasil, 13 de janeiro de 1976, Ed. 00278.
} 
A década de 1980 ficou conhecida por "década perdida" do ponto de vista econômico do crescimento e do desenvolvimento e terminou com uma hiperinflação. Este período também é marcado pela abertura política e pelo início de um novo tipo de espaço institucional para a arte: os centros culturais. A Galeria Banerj (1979), o Circo Voador (1981), Espaço Cultural Sergio Porto (1983), o Paço Imperial (1985), a Casa de Cultura Laura Alvim (1986) e o Centro Cultural Banco do Brasil (1989) são alguns exemplos. A galeria Saramenha de Victor Arruda no Shopping da Gávea, a galeria Thomas Chon na rua Barão da Torre, em frente a PG, e a nova galeria de Jean Boghici também em Ipanema, são referências importantes no Rio nos anos 80.

No decorrer da década de 1970 Terranova esteve à frente da Arte Global, em São Paulo, que figurou regularmente entre as galerias mais bem avaliadas pela crítica, realizando uma média de 13 exposições por ano. É possível observar na trajetória da PG um reflexo desta dedicação de Terranova a outros projetos - que levou inevitavelmente a ausências regulares nos assuntos da PG no Rio. Em 1981 a PG passa pela primeira grande crise desde os percalços enfrentados por Terranova nos anos 50. Ele explica nos jornais que a galeria entrará num "sono contemplativo"16 para uma "revisão ética e estética"17 e promove uma grande liquidação do acervo que foi anunciada no jornal como um "supermercado de arte"18.

A crise não foi exclusiva da PG, outras galerias também fecharam as portas durante os anos 80. Frederico Morais em sua coluna do Globo, onde divulga a programação das galerias para 1981, menciona a insegurança do sistema e inclui o comentário de uma galerista sem divulgar seu nome:

Estou com medo e preocupada com a crise econômica do país. Vejo automóveis estocados, desemprego, queda de poder aquisitivo. Eu não posso exigir do artista gastos com molduras, catálogos, convites, coquetel, que não são poucos, se não posso garantir-lhe a venda de suas obras. Prefiro trabalhar com meu acervo. (Frederico Morais, 0 Globo, 4 de janeiro de 1981, Matutina, Domingo, p. 4)

\footnotetext{
16 Júlio Bandeira, Mercado carioca de arte cai no sono, Jornal do Brasil, 1 de fevereiro de 1981, Ed.00297

17 Joana Angélica, 0 mercado de arte em questão, 11 de fevereiro de 1981, Matutina, Cultura, p. 25.

18 Jornal do Brasil, 1981, Ed. 00154
} 
A falta ou a má regulamentação do setor cultural, que já vinha sendo questionada desde o início dos anos 1970, estiveram no centro das discussões acerca da crise no mercado de arte no ano de 1981. 0 aumento do ICM de 1,5\% para 6,2\% e a regulamentação do Direito de Sequência que ficou conhecido como Lei dos 20\%19 foram as principais causas da discórdia. A isenção de imposto de renda para artistas, que vigorou entre o governo Vargas e o Médici, foi apontada como um possível incentivo mais proveitoso à classe artística. Em 1986 foi criada a Lei Sarney de renúncia fiscal para a área da cultura, que serviu de modelo para a atual Lei Rouanet.

Entre 1981 e 1983, o "sono contemplativo" e a "revisão ética e estética" de Terranova não significaram a interrupção das atividades da galeria. 0 processo de transformação institucional que aconteceu na década de 80 com o surgimento dos centros culturais esteve também no campo de visão do galerista/poeta.

O espaço que tenho hoje poderia ser utilizado para trabalhos de vanguarda, sem serem necessariamente herméticos. Minha ideia maior é, portanto, fazer do espaço um centro de atividades culturais, mas para isso precisaria de ter autorização especial do Estado. Viver de acervos e exposições não é financeiramente possível. (Franco Terranova para o Jornal do Brasil, 1981, Ed. 00152)

${ }^{19}$ A Lei dos 20\% estabelece que sempre que uma obra for vendida, por valor acima de um montante de 5 salários mínimos, o vendedor deve pagar 20\% sobre o lucro para o autor da obra ou para seus herdeiros. 


\section{A vocação cultural da PG e sua 4⿳亠丷⿵冂⿱十口 fase}

Desde as tertúlias na cave da galeria do Cine Rian nos anos 1950, a PG promoveu lançamentos de livros, cursos, recitais de música, palestras, debates, projeção de filmes, e outros eventos culturais em seus espaços. Os atravessamentos entre o campo da arte e o da cultura foram característicos do funcionamento da PG.

Em 1979, Rossella Terranova inaugura o Petit Studio (academia de pesquisa em dança, movimento e teatro instalada nos fundos da PG). A equipe inicial de professores contou com Regina Miranda (dança contemporânea), Klaus e Angel Vianna (movimento), Affonso Grisolli (teatro), Francisco Saba (Jazz), Rossella Terranova e Consuelo Rios (dança clássica).

Entre 1981 e o final de 1983 não aconteceram exposições na PG mas não significaram o fechamento da galeria. A experiência do Cabaret Voltaire ${ }^{20}$ - proposta pelos cineastas Júlio Bressane, Rogério Sganzerla e Syilvio Lana -, é o marco de início da $4^{\text {a }}$ fase da PG e ilustra a ampliação das atividades culturais. A ideia inicial previa uma semana de eventos, mas devido ao sucesso de público, o Cabaret Voltaire, que também foi chamado de Cineclube Brasil, se estendeu por 15 dias.

\footnotetext{
O objetivo é criar um detonador de idéias e imaginação - explica Julio Bressane Nós nos inspiramos no cabaré alemão, que vários artistas tomaram conta em 1916, criando um dos mais importantes movimentos de vanguarda artística - o Dadaísmo. Mas não pretendemos trazer pra cá a poeira de biblioteca européia: vamos fazer uma deglutição do que teria sido este movimento na Europa e usar a idéia central, combinando música, teatro, dança, poesia. (Julio Bressane em entrevista ao Jornal do Brasil, 1981, Ed. 00173)
}

Este momento de pausa reflexiva não foi tranquilo e causou certa confusão na imprensa. Terranova, quando anunciou a liquidação do acervo, chega a cogitar o encerramento da galeria e a possibilidade do espaço ser transformado em restaurante ou estacionamento. Como o terreno onde a casa da Barão da Torre foi construída era alugado, a manutenção do espaço era dispendiosa. Os proprietários do terreno constantemente reivindicavam a sua devolução.

20 Cabaret Voltaire: nome utilizado como citação à experiência dadaísta na Suíça em 1915. 
Para além da realização de eventos culturais, outra característica notável da $4^{\underline{a}}$ fase é a interrupção dos leilões, quando foram contabilizados apenas dois leilões além do supermercado de arte. A liquidação do acervo pode ser identificada como um marco na transição para a última fase da galeria e teve relação com a crise econômica que fustigou o Brasil na década de 1980. A partir do fim de 1983 a PG volta a realizar exposições, no ano de 1986 a galeria apresenta uma programação intensa com 18 exposições. Entre 1984 e 1988 a PG organiza 50 exposições até o seu encerramento.

Os anos 80 são cenário de um reconhecido retorno à pintura. Este fenômeno não foi um caso isolado no Brasil. O crítico italiano Bonito Oliva cunha o termo Transvanguarda para a produção de pintura emergente na década de 80. Análises também apontam a apropriação pelo mercado deste retorno à pintura como estratégia de valorização de uma produção vendável diante do experimentalismo dos anos 70. No entanto, a visão segundo a qual a produção dos anos 80 foi restrita à pintura pode ser entendida como reducionista. Mesmo a exposição Como vai você Geração 80?, que aconteceu no Parque Lage em 1984, não deve ser tomada como uma mostra exclusiva de pintura. Artistas como Ricardo Basbaum, Barrão e Cristina Salgado, por exemplo, participaram da mostra e não apresentaram pinturas ${ }^{21}$.

No final de 1983 a PG volta a organizar exposições. 0 entusiasmo característico de Terranova pela produção de jovens artistas marca o inicio desta nova etapa com a primeira exposição individual de Cristina Salgado (desenhos e pinturas). A partir desta mostra a artista inicia sua pesquisa tridimensional. A relação entre artista e galerista proporcionou a percepção, no processo de Cristina, do recorte de seu vocabulário pessoal. 0 material para a obra Mulher em pedaços, elaborada para a exposição Como vai você geração 80?, foi financiado por Terranova como parte do incentivo no desenvolvimento de seu trabalho.

\footnotetext{
${ }^{21}$ Basbaum, como artista e teórico pertencente a esta geração, vem questionando a ideia de pintura como produção hegemônica na década de 80. Os textos Pintura nos Anos 80: algumas observações críticas, Tornando visível a arte contemporânea, 2080: muito mercado e pouca arte e Regiões de sombra dos 80 são alguns textos onde ele trata de questões em torno disso. Uma das questões enfatizadas em seus textos é a necessidade do embate direto com a obra para uma avaliação não generalizante. Ele aponta a pintura como mais uma ferramenta de linguagem dentro do repertório artístico disponível a partir das conquistas das décadas de 60 e 70.
} 
A PG não deixou de participar diretamente na discussão em torno da pintura. Em 1984 acontece a coletiva Viva a pintura idealizada por Rubens Gerchman em homenagem a Iberê Camargo. A mostra conta com catálogo contendo texto crítico de Wilson Coutinho. Participaram da mostra: Adriano de Aquino, Angelo de Aquino, Carlos Zilio, Charles Watson, Claudio Kuperman, Claudio Tozzi, Dudi Maia Rosa, Enéas Valle, Iberê Camargo, Ivald Granato, Jorge Guinle, Luiz Aquila, Luiz Paulo Baravelli, Paulo Garcez, Roberto Magalhães e Rubens Gerchman.

Em 1987, acontece a exposição coletiva Nova Escultura, dela participam Barrão, Angelo Venosa, Jac Leirner, Luiz Pizarro, Cristina Salgado e Ernesto Neto. Jorge Barrão, então com 28 anos, é destaque da mostra segundo o jornal 0 Globo.

Dentro das muitas maneiras de discutir a arte e como um de seus meios, a pintura, é possível observar a exposição Cinza de Cildo Meireles, trabalho instalativo que se refere à história da pintura. 0 projeto apresentado em 1984 na galeria Luiza Strina em São Paulo foi mostrado na PG em 1986.

No âmbito das questões da pintura as exposições de pinturas e desenhos de Artur Barrio apresentadas na PG são um exemplo observável. Em 1985, Barrio apresenta pela primeira vez uma mostra somente de pinturas na PG. Em 1986 realiza outra individual apresentando desenhos e pinturas. Mesmo o trabalho de Barrio sendo conhecido pela contestação de suportes tradicionais, nota-se que a escolha do suporte na obra de Barrio é conjuntural, sendo apenas ferramenta e não um fim específico.

A característica de programação híbrida da galeria, que se estendeu durante seus 34 anos de percurso pode ser observada na década de 80 com exposições desde Dionísio Del Santo, passando pela coletiva em homenagem a Maria Leontina ou pela mostra instalativa Cinza de Cildo Meireles. Entre os artistas jovens lançados neste período destacam-se Frida Baranec, Luiz Pizarro, Hidelbrando de Castro, Alexandre Dacosta, Sérgio Romagnolo e Ernesto Neto. 


\section{0 fechamento da galeria e $O$ Eterno Efêmero}

Em 1988 a galeria da Barão da Torre fecha suas portas. No contexto do fim da galeria, o evento de encerramento serve de inspiração. Subvertendo o espaço tradicional do "cubo branco" e buscando quebrar o fetiche em torno da obra de arte eterna, o happening idealizado por Terranova consistiu em convidar 59 amigos-artistas para interferirem diretamente sobre as paredes da galeria. A ação que durou uma semana foi chamada por Terranova de $O$ Eterno Efêmero.

A realização dos trabalhos foi aberta, durante uma semana o público pôde ver os artistas trabalharam lado a lado. Várias gerações de artistas participaram da festa em torno de seu anfitrião que esteve presente durante toda a semana. "De Iberê Camargo a Daniel Senise, de Aluisio Carvão a Frida Baranek, de Abraham Palatinik e Franz Weissmann a Roberto Magalhães, Vergara e tantos outros": com esta constelação Ligia Canongia inicia sua coluna no Segundo Caderno de O Globo sobre a despedida da PG.

Depois de três dias de trabalho e dois dias de exposição tudo foi novamente pintado de branco numa catarse coletiva. Todo o processo foi registrado em vídeo com a câmera de Marco Terranova e edição da jornalista Teresa Cristina Rodrigues. Durante 4 dias, a grande sala da PG, já novamente branca, serviu pela última vez de suporte para a exibição do registro em vídeo chamado In-Finito, Eterno Efêmero.

O acontecimento foi largamente comentado na imprensa. Terranova, naquele momento, tinha fortes planos de empreender um novo espaço de arte na Barra da Tijuca, bairro que considerava promissor na cidade. Ângelo de Aquino em depoimento ao Jornal O Globo diz: "mesmo que esta ruptura seja temporária Franco deve estar satisfeito por tudo aquilo que desenvolveu, por todas as oportunidades que deu a artistas que causavam certo constrangimento com suas obras inovadores" (O Globo, 8/7/1988). Luiz Áquila reforça: "Ele é um homem extremamente importante para as artes plásticas, principalmente porque teve coragem de investir em artistas jovens e desconhecidos, movido por sua intuição, sensibilidade e olho clínico" (Jornal do Brasil, 8/7/1988, Ed. 00091). 
O desejo de criar um novo espaço que conjugasse todas as artes e ainda assim viabilizasse financeiramente o seu trabalho e o dos artistas, não chagou a acontecer. Em 1988, o prefeito da cidade do Rio de Janeiro, Saturnino Braga, decretou a falência do município. A crise econômica que assolou o Brasil, marcada pelo Plano Collor em 1989 e pela hiperinflação que atingiu níveis nunca imaginados, durou muito mais do que se poderia supor. Neste cenário hostil, o encerramento do ciclo da PG possibilitou que Franco Terranova, enfim, pudesse se dedicar a sua outra paixão, a escrita, deixando-nos mais de 10 livros publicados.

O ponto onde funcionou a PG na rua Barão da Torre foi adquirido pelo marchand José Otávio Montesanti. A ocupação do espaço onde funcionou a PG como uma galeria de arte foi breve, a casa acaba por servir de expansão para a churrascaria Porcão que já funcionava ao lado. 0 grande terreno onde estiveram instalados a PG, o Petit Studio, o curso de inglês Britannia e o Porcão pertenciam à mesma família, que durante anos tentou despejar a PG. Em 2018 todos os imóveis existentes no terreno foram demolidos e um shopping center começou a ser construído no local.

\section{Conclusão}

Segundo Frederico Morais, no texto escrito para o catálogo da exposição Petite Galerie: uma visão da arte brasileira realizada no Paço Imperial em 1996, a trajetória da galeria, em suas quase quatro décadas de funcionamento, pode ilustrar as relações entre mercado de arte, o crescimento econômico e a vida cultural da cidade do Rio de Janeiro. Este diálogo, sempre mediado pela personalidade de Franco Terranova, fez parte do desenvolvimento do circuito de arte no Rio de Janeiro e no Brasil, sendo a galeria pioneira no agenciamento de artistas, contratos de exclusividade e na implantação de técnicas de marketing cultural (leilões a prazo e financiamento de obras, divulgação de eventos comerciais de arte em anúncios de jornal e divulgação da arte nos meios financeiros que não tinham tradição de entender arte como investimento). Ao observar o diálogo da PG com o desenvolvimento da arte produzida no Brasil na segunda metade do século XX, é 
possível perceber seu papel como agente de ativação em todo o seu período de funcionamento, pelo incentivo à divulgação de novos artistas, o desenvolvimento de novas técnicas comerciais e a abertura aos cruzamentos entre os muitos fazeres da arte e da cultura.

\section{Referências}

BASBAUM, Ricardo. Pintura nos anos 80: Algumas observações críticas. In Arte Contemporânea brasileira: texturas, dicções, ficções estratégicas. Ricardo Basbaum (org.). Rio de Janeiro: Rios Ambiciosos, 2001.

. Manual do artista-etc / Ricardo Roclaw Basbaum. 1. ed. - Rio de Janeiro : Beco do Azougue, 2013.

BITENCOURT, Francisco. ; [organização e textos; Fernanda Lopes e Aristóteles Angheben Predebon] - Rio de Janeiro : Tupinambá_Arte, 2016.

MORAIS, Frederico. Cronologia das artes plásticas no Rio de Janeiro, 1816-1994 / Frederico Morais. - Rio de Janeiro: Top-books, 1995.

. PG. In Petite Galerie 1954-1988: uma visão da arte brasileira. Paço Imperial no Rio de Janeiro, 1996.

OITICICA, Hélio. Esquema Geral da Nova Objetividade. In. Escritos de Artistas: Anos 60/70 / seleção a comentários Glória ferreira e Cecília Cotrim; [tradução de Pedro Sussekind... et al.]. - Rio de Janeiro Zahar, 2006.

Projeto HO Itaú Cultural, Número de Tombo: 0101/77

Acesso em 21 de jul. de 2018:

http://54.232.114.233/extranet/enciclopedia/ho/index.cfm?fuseaction=documen tos $\&$ cod $=245 \&$ tipo $=2$

Petite Galerie 1954 - 1988: uma visão da arte brasileira, catálogo da exposição realizada no Paço Imperial no Rio de Janeiro em 1996.

ZILIO, Carlos. REZENDE, José. BRITO, Ronaldo. CALDAS, Waltercio. $O$ boom, o pósboom e o dis-boom. In Arte contemporânea brasileira: texturas. Dicções, ficções estratégicas. Ricardo Basbaum (org.) - Rio de Janeiro: Rios Ambiciosos, 2001.

Recebido em: 15/11/2018

Aprovado em: 17/11/2018 